\title{
The opinion of sports science professionals for the benefit of statistics: an international web-based survey
}

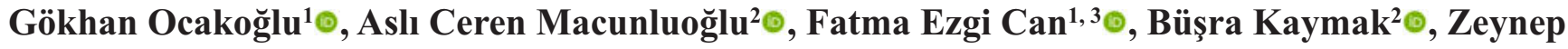 \\ Yivlik $^{4} \odot$
}

${ }^{1}$ Department of Biostatistics, Uludağ University School of Medicine, Bursa, Turkey

${ }^{2}$ Department of Biostatistics, Institute of Health Sciences, Uludağ University, Bursa, Turkey

${ }^{3}$ Department of Biostatistics and Medical Informatics, Katip Çelebi University School of Medicine, İzmir, Turkey

${ }^{4}$ Department of Biostatistics and Medical Informatics, İstanbul University School of Medicine, Istanbul Turkey

\begin{abstract}
Objectives: The present study, an international web-based survey, was focused on four aims: to obtain sports science professional's self-reported statistical knowledge levels and how this knowledge varies by research area, to investigate and specify when statistics courses should be taught in sports science education and to identify the key statistical methods relevant to sports science education.

Methods: In the present study, sports science professional data obtained by a web-based survey. Participants were selected randomly from the PubMed (www.ncbi.nlm.nih.gov) database for the years 2010-2018 using the keywords "school of sports science, faculty of sports science, sports faculty" by screening the sports science journals. Therefore, the participants were determined by searching the keywords in the corresponding or the first author's address information of the articles.

Results: The results indicate that while sports science professionals emphasize statistics education and the participants also believe that taking a statistics course is useful for their occupation. A statistics education should also emphasize the necessity of statistical consultation.

Conclusions: Our study provides information regarding self-reported levels of statistical knowledge of sports science professionals by research area and academic position, and provides guidance regarding the ideal semester for administering a statistics course.

Keywords: Statistics course, statistics knowledge, sports science education, sports science professionals, webbased survey
\end{abstract}

$\mathrm{T}$ he acceptance of the results obtained from scientific research depends on the correct interpretation of the findings obtained by appropriate statistical analysis. In the generalizability process of the results; if statistics is considered as a tool, this tool must be used correctly and consciously. The fact that every step of scientific research from planning to the interpretation of results includes statistics, this tool leads to the integration of itself into various disci- plines. Since scientific journals are aware of this fact and do not want to compromise on the statistical quality of the work they publish, they also include statistics or biostatistics editors in the editorial team. This importance given by scientific journals to the statistics requires the authors and readers should have at least a basic knowledge of statistics to be able to publish their work and benefit from the studies published in these journals that want to maintain this quality [1]. Many

How to cite this article: Ocakoğlu G, Macunluoğlu AC, Can FE, Kaymak B, Yivlik Z. The opinion of sports science professionals for the benefit of statistics: an international web-based survey. Eur Res J 2020;6(2):145-153. DOI: 10.18621/eurj.468686

Address for correspondence: Gökhan Ocakoğlu, PhD., Associate Professor, Uludağ University School of Medicine, Department of Biostatistics, Bursa, Turkey.E-mail: ocakoglu@uludag.edu.tr,Tel: +902242953871 
studies in the literature evaluated the importance given to statistics according to various disciplines. While some of these studies [2-6] examined the importance of statistics regarding the authors who submitted their studies to the journals, some of them [7-13] focused on the statistical errors in the articles published in scientific journals and aimed to emphasize the importance given to the statistics regarding journals. In addition to this statistics-based press, scientific journals sometimes try to fulfill their mission by publishing articles aimed at informing their readers about basic statistical concepts and sometimes informing them about the advanced statistical methods specific to their disciplines. Despite these positive initiatives, the effort and pressure to increase the number of publications produced in the academic environment, unfortunately, sometimes violate the scientific framework based on the concepts of rigor, repeatability, and transparency [14].

By applying statistical methods to various disciplines, statistical methods specific to the fields have emerged, and thus, the science of statistics has been integrated into many fields. One of the integrated fields of statistics science is sports sciences. As a result of this integration Casals and Finch [15], mentioned the fields of specializations that are specific to statistics and sports science as sabermetrics, Moneyball, sports analyst,and sports biostatistician. As in every discipline, the place of statistics in sports sciences is also important for the view of selecting the appropriate statistical procedure, to analyzing data, to the presentation of results. Moreover, this importance is directly proportional to the statistics education administered at the undergraduate and graduate level and the need for statistics in the publication stage of studies in scientific journals.For this reason, our study focused on sports science professionals with a $\mathrm{PhD}$. degree.Therefore, participants just with a bachelor's or master's degree excluded from the evaluation.

The present study, an international web-based survey, was focused on four aims: to obtain sportsscienceresearchers' self-reported statistical knowledge levels and how this knowledge varies by research area, to investigate and specify when statistics courses should be taught in sports science education and to identify the key statistical methods relevant to this education process.

\section{METHODS}

In the present study, sports science professional data obtained by a web-based survey. Participants were selected randomly from the PubMed (www.ncbi.nlm.nih.gov) database for the years 20102018 using the keywords "school of sports science,faculty of sports science, sports faculty" by screening the sports science journals. Therefore, the participants weredetermined by searching the keywords in the corresponding or the first author's address information of the articles.After the identification of the participants, they were also confirmed to be sports science professionals from their institutional web page ortheir previous studies. The participants were invited to participate in the survey via e-mail, and the respondentswere directed to the survey at SurveyMonkey (https://www.surveymonkey.com).

In the first part of the survey, subjects were asked whether a statistics or biostatistics course would be useful for their future careers (from "completely disagree: 1"; to "completely agree: 5"), at which semester or semesters should statistics or biostatistics be administered, and how much importance they placed on statistics (from "not important: 0"; to "very important: 10"). In the second section of the survey, the subjects were asked which statistical methods, tests and techniques they knew, out of 54 methods and techniques which referenced based on our previous studies [2-5]. Only self-reported general knowledge about the procedures was assessed. In the questionnaire, methods, tests and techniques were grouped as "general statistics knowledge". Subgroup statistical methods, tests and techniques were classified as follows: "parametric tests", "nonparametric tests", "multivariate methods", "sampling methods" and "survival analysis methods". The selfreported statistics knowledge of each participant was converted to a ratio by dividing the number of methods, tests, and techniques that the participant knew by the total number of methods, tests and techniques in that subject group.

\section{Statistical Analysis}

In this study, the Shapiro-Wilk normality test was applied to determine whether the variables were 
normally distributed. For comparison, Analysis of Variance (ANOVA), Kruskal-Wallis test, Independent samples t-test and Mann-Whitney U test were applied using a significance level of $\alpha=0.05$. Data were presented with median and interquartile range (IQR) which is equal to the difference between the $25^{\text {th }}$ and $75^{\text {th }}$ percentile value and also supported with mean \pm standard deviation values. The relation between categorical variables was examined using correlation analysis, and Spearman correlation coefficient was computed. Statistical analyses performed by using SPSS (IBM Corp. Released 2012. IBM SPSS Statistics for Windows, Version 21.0. Armonk, NY: IBM Corp.).

\section{RESULTS}

Of the 2089 e-mail invitations sent, 123were rejected by the server due to e-mail addresses being either incorrectly spelled or no longer valid, leaving an estimated1, 966 e-mail recipients. Those who responded with the intention of participating numbered 166, reflecting a response rate of $8.44 \%$. Additionally, of 166 respondents, 29 were excluded from the study due to their failure to complete the survey.

Participants mean age was $24.80 \pm 8.98$ years (range: 26 to 70 years). The majority of participants were male $(n=102,74.48 \%)$. Socio-demographic characteristics of the participants presented in Table 1.
Table1. Socio-demographic features of the participants

\begin{tabular}{|c|c|}
\hline \multicolumn{2}{|l|}{ Age } \\
\hline Mean \pm Std. Deviation & $24.80 \pm 8.98$ \\
\hline Minimum: Maximum & $26: 70$ \\
\hline \multicolumn{2}{|l|}{ Gender, n (\%) } \\
\hline Female & $35(25.55 \%)$ \\
\hline Male & $102(74.45 \%)$ \\
\hline \multicolumn{2}{|l|}{ Academic Rank, n (\%) } \\
\hline Professor & $27(19.71 \%)$ \\
\hline Associate Professor & $36(26.28 \%)$ \\
\hline Assistant Professor & $46(33.58 \%)$ \\
\hline Lecturer & $28(20.44 \%)$ \\
\hline \multicolumn{2}{|l|}{ Academic, n (\%) } \\
\hline Academic & $109(79.56 \%)$ \\
\hline Non- Academic & $28(20.44 \%)$ \\
\hline
\end{tabular}

A total of 137 sports science researchers from five continents and 38 countries participated in our study (Table 2).

Of the total 137 participants, 109 (79.56\%) were academic staff, and 28 (20.44\%) were not. All of 137 participants had a $\mathrm{PhD}$. degree. Nearly $41 \%$ of the participants $(n=55)$ stated that they hadadministereda statistics course in postgraduate education. The second most chosen option was determined by those $(n=52$, $37.96 \%$ ) who administered the course at both the

Table 2. Distribution of the participants according to continents and countries

\begin{tabular}{cc}
\hline Continent & Country \\
\hline Africa & Egypt (1), South Africa (1), Uganda (1) \\
$\mathrm{n}=3(2.19 \%)$ & Brazil (12), Portugal (3), Mexico (2), Peru (1), Trinidad and Tobago \\
America & (1), United States (1) \\
$\mathrm{n}=20(14.60 \%)$ & Turkey (28), Iran (10), Japan (5), Taiwan (1), Austria (1), China (1), \\
Asia & Kuwait (1), Republic of Korea(1), Thailand (1), Turkmenistan (1) \\
$\mathrm{n}=50(36.50 \%)$ & Greece (15), Spain (12), Italy (11), Croatia (4), France (3), United \\
Europe & Kingdom (3), Germany (2), Sweden (2), Switzerland (2), Czech \\
$\mathrm{n}=63(45.99 \%)$ & Republic (1), Hungary (1), Ireland (1), Lithuania (1), Luxembourg (1), \\
& Netherlands (1), Poland (1), Romania (1), Macedonia (1) \\
Oceania & Australia (1) \\
$\mathrm{n}=1(0.73 \%)$ & \\
\hline
\end{tabular}




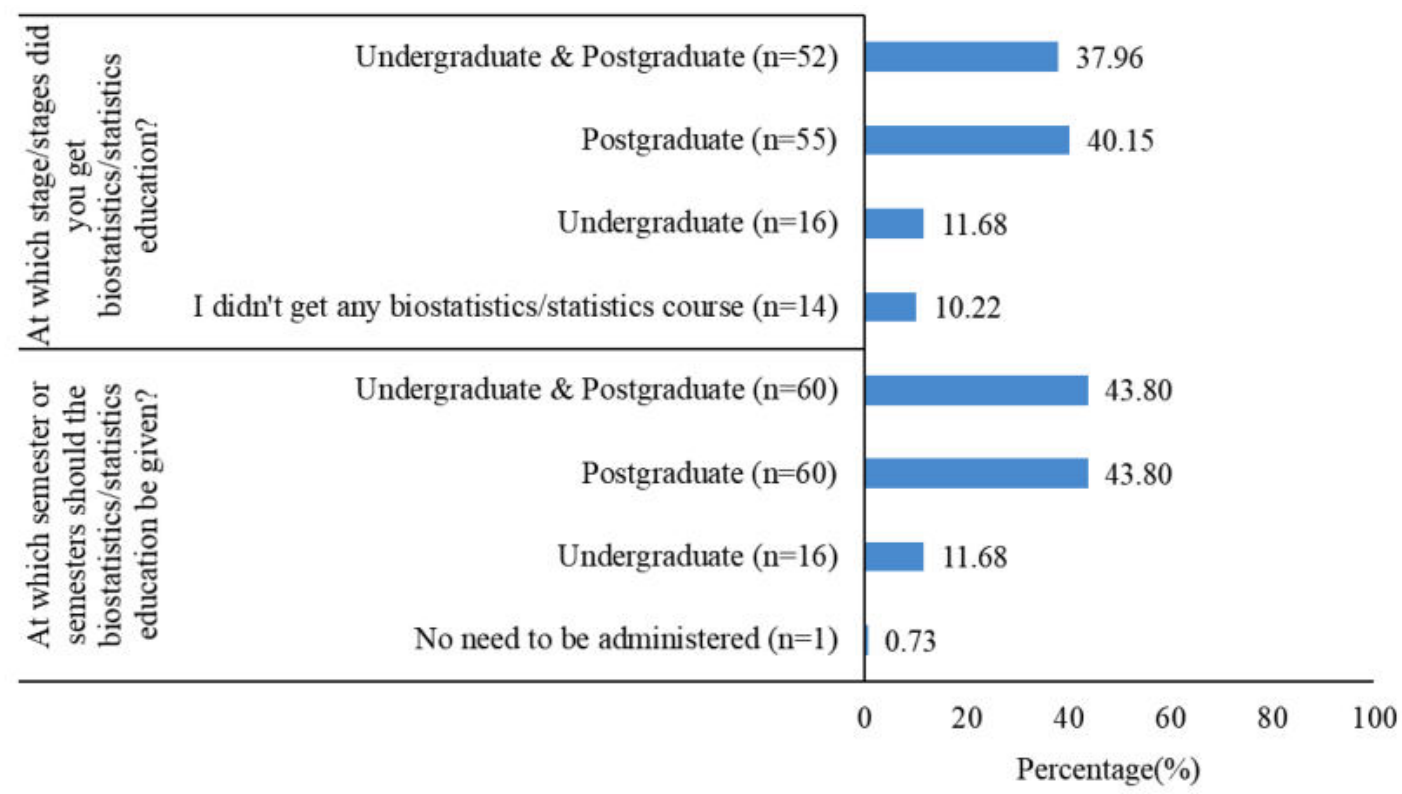

Fig. 1. Percentage of when the participants enrolled a biostatistics course and preferred time line.

Table 3. Descriptive values and comparisons of whether enrolling in a statistical/biostatistics course are useful for one's occupation and the importance placed on biostatistics in sports science according to academic staff and research area

\begin{tabular}{lcc}
\hline & $\begin{array}{c}\text { Do you agree with the idea of } \\
\text { taking statistics course of a sports } \\
\text { science researcher is useful for } \\
\text { his/her occupation? } \\
\text { (min-max:1-5) }\end{array}$ & $\begin{array}{c}\text { What is the importance of } \\
\text { statistics in sports sciences? } \\
\text { (min-max:0-10) }\end{array}$ \\
\hline Academic Statue & $5(1)$ & $10(2)$ \\
\hline Academic Staff $(\mathrm{n}=109)$ & $4.35 \pm 1.04$ & $9.01 \pm 1.29$ \\
\hline Non-academic Staff $(\mathrm{n}=28)$ & $4.50(1)$ & $8.50(2)$ \\
\hline$p$-value & $4.21 \pm 0.99$ & $8.43 \pm 1.83$ \\
Research Area & $0.299^{\mathrm{a}}$ & $0.061^{\mathrm{a}}$ \\
Exercise Physiology $(\mathrm{n}=60)$ & $5(1)$ & $10(2)$ \\
& $4.23 \pm 1.11$ & $8.95 \pm 1.55$ \\
Physical Performance $(\mathrm{n}=39)$ & $5(1)$ & $9(2)$ \\
Physical Education $(\mathrm{n}=23)$ & $4.41 \pm 0.88$ & $8.85 \pm 1.39$ \\
& $5(1)$ & $9(2)$ \\
\hline Department of Coaching and & $4.22 \pm 1.04$ & $8.78 \pm 1.41$ \\
Psychology ( $\mathrm{n}=6)$ & $5(1.75)$ & $8.50(2.25)$ \\
$p$-value & $4.17 \pm 1.60$ & $8.33 \pm 1.21$ \\
\hline
\end{tabular}

Data were presented as Median (Interquartile range) and Mean \pm Std. Deviation. ${ }^{\mathrm{a}}=$ Mann Whitney U test, ${ }^{\mathrm{b}}=$ Kruskal Wallis test; Trainer Education $(n=4)$, Sports Management $(n=3)$, Recreation $(n=2)$ due to insufficient sample size these groups were excluded from the analysis. 


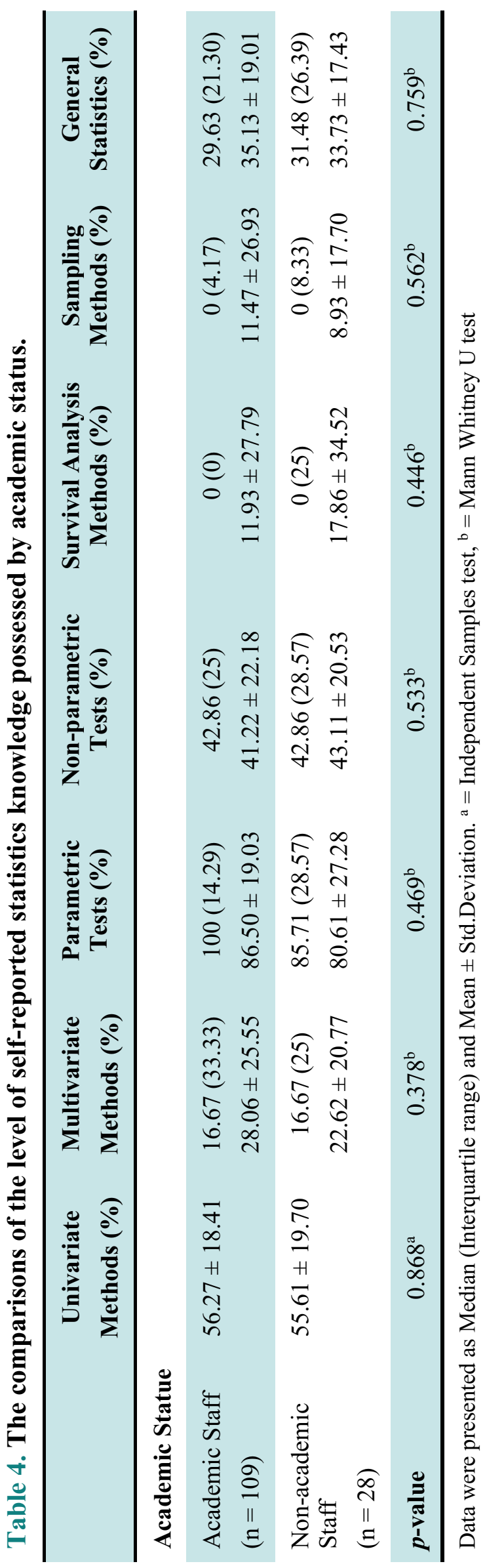

undergraduate and graduate level. The distribution of the responses of the remaining participants as follows: $11.68 \%(\mathrm{n}=16)$ took a biostatistics course only during undergraduate education, and the remaining $10.22 \%(n=14)$ stated that they never took a statistics or biostatistics course (Fig. 1).

Two of the preferences of the period in which the course should be taken were surprisingly the same and the highest ratio with $43.80 \%(n=60)$. The rest of the preferred opinions were as follows: $11.68 \%(n=16)$ of the participants preferred that the course isadministered only at the undergraduate level, and $0.73 \%(n=1)$ stated that there was no need to administer the course (Fig. 1).

It was determined that SPSS is the most preferred statistical software for statistical analysis (Fig. 2). The three most-preferred statistical software are as follows: SPSS (65.96\%), STATISTICA (9.22\%) and LISREL\&GraphPad (3.55\%).

Academic participants which include staff personnel who hold an academic rank with titles such as professor, associate professor, assistant professor, instructor, lecturer, or the equivalent of any of these academic ranksand non-academic participants think that the statistics course is very important for them and that administering the course will benefit the profession in the future (Table 3). There was no difference in responses between academic and nonacademic staff. Furthermore, all participants also agreed on the importance of statistics with the median point 9 (IQR: 2). Regardless of whether they were academic staff or not, there was also no difference between participant's responses to the importance of statistics and its usefulness, even when examined only in the research area of sports science (Table 3 ).

There is no difference between the academic and the non-academic staff according to the self-reported informationlevel (Table 4). Moreover, there is also no difference between the research areasaccording to the self-reportedknowledge levels (Table 5).

There is a relationship between the number of studies that participants place in the first order and their statistical knowledge levels. With the increase in the level of knowledge of the participants about general statistics, multivariate methods and parametric tests, the number of publications they are in the first order are increasing (Table 6). 


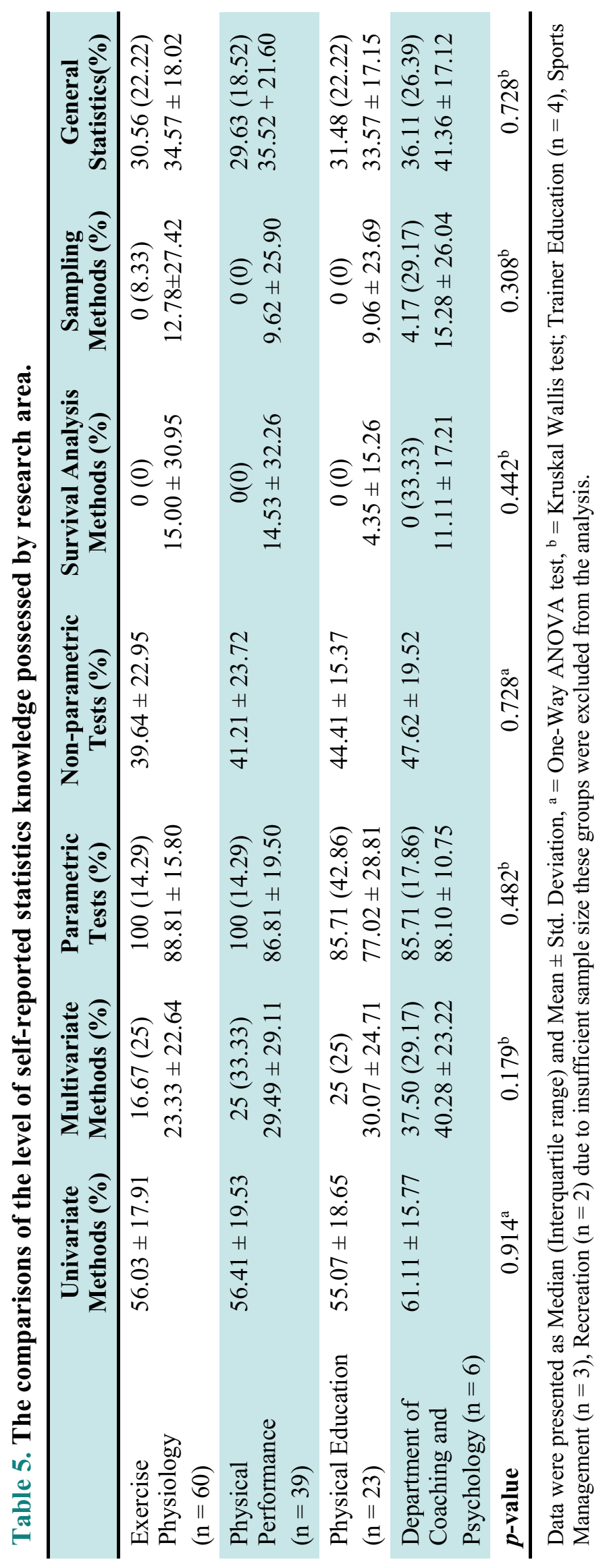

\section{DISCUSSION}

The science of statistics is constantly evolving, and the products that it creates as a result of its cooperation with different disciplines make statistics popular. Understanding statistical concepts and skills are very important for those who read and publish scientific articles $[1,16]$. A statistician who is proficient in instruments and uses in statistics science can use these features to specialize in his field.

As in every branch where statistics act together, statistics are of great importance for sports sciences. In the present study, it is aimed to examine whether this importance has changed according to the subbranches of sports sciences and whether the participants are academic staff or not. Similar to our previous studies [2-6], it is seen that statistics (to the biostatistics in the sports sciences undergraduate and graduate education curriculum) are also given importance in sports sciences. However, this emphasis on statistics did not differ according to whether the participants were academic staff or not. Beyond the difference between academic and non-academic staff members, regarding the importance of statistics course and the role in career advancement, there was also no difference among research areas of sports science professionals. There is a clear distinction between the participants according to their opinions about when the course should be given. Almost half of the participants stated that they took the course only during the undergraduate term; the other group, who had a similar rate, stated that they took the course both in undergraduate and postgraduate periods. Since the present study is also multinational, it is likely that the undergraduate and graduate curricula that include the statistical course vary from country to country. Also, this finding is consistent with previous studies [2-5]. As in medicine, veterinary, dentistry and nursing; it is not surprising to see that the importance of statistics is also given in sports sciences.

Ten percent of the participants in our study stated that they did not take the course of statistics throughout their education. This can be interpreted that the remaining participants experience at least one statistical software during the application in the application of statistics or biostatistics course. With the experience of our previous studies, researchers 


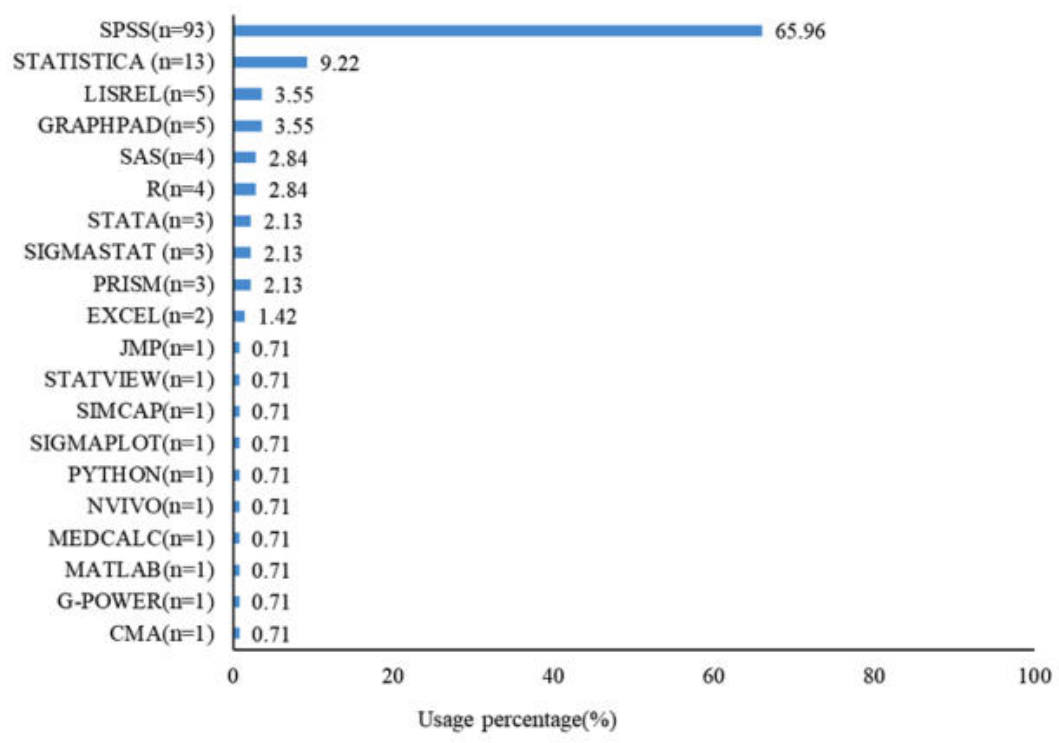

Fig. 2. Usage percentage of preferred statistical software by sports science researchers.

tend to prefer statistical software with the user interface in their work. As in our previous studies [25], SPSS is the software that the participants prefer in statistical analysis. In our study, as in our previous studies, participants highlighted the SPSS program as a tool to transfer their statistical skills to their scientific research.

It is known that biostatistics or statistics courses are considered a cautious course by professionals, especially in health sciences, and they do not have the necessary importance in postgraduate education $[17$, 18]. The fact that the required importance is not given to the statistics course and that the required interest is not shown, causes a lack of basic level of statistics to be felt especially in the case of an academic career.
Emphasizing the importance of statistics by the researchers involved in our previous studies may be a potential consequence of this lack. Also, it should be kept in mind that the deficiency felt against the statistics can be explained by the general lack of knowledge, but also by the inadequacy of specific techniques. In our study, the participants were asked to indicate which of the subtitles included in the statistical techniques, and the awareness levels about the statistics were tried to be measured. There was no difference between academic and non-academic sports science professionals regarding self-reported knowledge of statistics subjects.

Moreover, there was no difference in the level of knowledge by a sports science professional's research

Table 6. The relationship between the participants' knowledge of statistical methods and their number of published articles

\begin{tabular}{lcc}
\hline $\mathbf{n}=\mathbf{1 3 7})$ & $\begin{array}{c}\text { Number of total published articles } \\
\text { (listed as the first author) }\end{array}$ \\
\hline Statistics subjects & $\mathbf{r}_{\mathbf{s}}$ & $\boldsymbol{p}$-value \\
General Statistics & 0.249 & $\mathbf{0 . 0 0 3}$ \\
Multivariate Methods & 0.269 & $\mathbf{0 . 0 0 2}$ \\
ParametricTests & 0.249 & $\mathbf{0 . 0 0 3}$ \\
Non-parametric Tests & 0.160 & 0.062 \\
Survival Analysis Methods & 0.087 & 0.312 \\
Sampling Methods & 0.070 & 0.415 \\
\hline
\end{tabular}

r: Spearman Correlation Coefficient 
areas. A noteworthy finding is that both academic and non-academic staff have high levels of self-reported knowledge about parametric tests. To use parametric tests, some assumptions such as normality or homogeneity of variances should be provided. In contrast to the parametric tests, the relatively low level of self-reported knowledge of the participants about nonparametric tests necessitates the questioning of their ability to distinguish between parametric and non-parametric tests. The use of nonparametric tests where parametric tests should be applied will result in loss of power and questioning of the findings obtained fromthe analyzes [19-21]. The highest level of knowledge of the participants after parametric tests is about univariate analysis methods.

Moreover, it is seen that the participants know nonparametric tests even though below average. When Table 4 and Table 5 are examined, it is seen that the level of general self-reported statistical knowledge of the participants is low. Another finding that did not surprise us in our study and was confirmed by our previous studies [2-4] is that the level of knowledge about sampling is quite low. The finding that sport science professionals are almost completely unaware of sampling techniques is somewhat unsettling because sampling is the first important topic that a researcher considers during the planning stage of the study. Researchers hope that the data collected from given samples and its interpretation will accurately reflect the conditions found in the general population or group [1]. For this reason, to make a consistent, efficient and unbiased prediction at the end of a study, it is important to apply sampling techniques accurately [3].

When we investigated the relationship between sports science professionals' self-reported knowledge level of statistical methods and the number of articles they published, there was a significant relationship between the participants' knowledge of univariate methods, multivariate methods and general statistical knowledgewith the number of articles they published. This finding indicates that the number of first name publications of the participants increased with the increase in the level of knowledge in the related titles. Considering the level of awareness of the participants about statistics, it is recommended that scientific studies should be carried out with an expert from the planning stage to the reporting stage. It is important to remember that the design of each study and the characteristics of the data obtained may be different and specific to a particular study, so each study may require different statistical methods with which the researchers may be unfamiliar [3]. In this aspect, collaboration of statisticians or biostatisticians is essential.

\section{Limitations}

One of the main limitations of this study is the low response rate $(<10 \%)$. The low response rate is not surprising, given that response rates to surveys have dramatically declined over time, due to the proliferation of junk mail, the rapid growth and ease of large-scale surveys, and resulting complaints that people feel "bombarded" with Internet-based surveys in the face of increasing demands on their time [22]. However, our response rate of $8.44 \%$ is similar to that of web-based studies in previous research aimed at nursing professionals $(5.07 \%)$ [5], academic veterinarians $(4.38 \%)$ [2], primary care physicians (5.7\%) [23], dental physicians (9.1\%) [3], and a group of urologists $(9.3 \%)$ [24]. When similar studies are considered, our response rate is acceptable.

\section{CONCLUSION}

The present study is significant regardingits international scope, intent and originality due to the uniqueness of this scope. Our study provides information regarding self-reported levels of statistical knowledge of sports science professionals by research area and academic positionand provides guidance regarding the ideal semester for administering a statistics course. This study can also contribute to revising higher education sports science curricula by including frequently used statistical methods as a part of sports science research to enable professionals to understand current research and contribute to its ongoing discussion.

\section{Conflict of interest}

The authors disclosed no conflict of interest during the preparation or publication of this manuscript.

\section{Financing}

The authors disclosed that they did not receive any grant during conduction or writing of this study. 


\section{REFERENCES}

1. Moskowitz E. Statistics in dentistry. Who needs them? N Y State Dent J 2007;73:4.

2. Ocakoğlu G, Ercan İ, Kaya MO, Uzabacı E, Can FE. Investigating academic veterinarians' knowledge of biostatistics: a web-based survey. Ankara Üniv Vet Fak Derg 2015;62:223-8. 3. Ocakoglu G, Ercan I, Gunel Karadeniz P. Knowledge of dentists about biostatistics: a worldwide survey. e-J Dent 2013;3:361-70.

4. Ercan İ, Ocakoğlu G, Özkaya G, Sığırlı D, Cangür Ş, Günel Karadeniz P. An international survey of physicians' knowledge of biostatistics. Turkiye Klinikleri J Med Sci 2013;33:401-9.

5. Ocakoğlu G, Kaya MO, Can FE, Atış S, Macunluoğlu AC. Nursing professionals' attitudes toward biostatistics: an international web-based survey. Eur Res J 2019;5:326-34.

6. Ercan I, Ozkaya G, Ocakoglu G, Yazici B, Sezer A, Ediz B, et al. Determining biostatistics knowledge of students and physicians in medical school. InterStat 2008;3:1-17.

7. Ercan İ, Ocakoğlu G, Sığırlı D, Özkaya G. Assessment of submitted manuscripts in medical sciences according to statistical errors. Turkiye Klinikleri J Med Sci 2012;32:1381-7.

8. Ercan I, Gunel Karadeniz P, Cangur S, Özkaya G, Demirtas H. Examining of published articles with respect to statistical errors in medical sciences. Int J Hematol Oncol 2015;27:130-8. 9. Ercan I, Kaya MO, Uzabaci E, Mankir S, Can FE, Bashir Albishir M. Examination of published articles with respect to statistical errors in veterinary sciences. Acta Vet Beograd 2017;67:33-42.

10. MacArthur RD, Jackson GG. An evaluation of the use of statistical methodology in the Journal of Infectious Diseases. J Infect Dis 1984;149:349-54.

11. McGuigan SM. The use of statistics in the British Journal of Psychiatry. Br J Psychiatr 1995;167:683-8.

12. Welch GE 2nd, Gabbe SG. Review of statistics usage in the American Journal of Obstetrics and Gynecology. Am J Obstet Gynecol 1996;175:1138-41.

13. Ahn W. Statistical methods in the articles in the Korean Journal of Anesthesiology published from 1994 to 1998. Korean
J Anesthesiol 2000;39:706-11.

14. Chambers CD, Feredoes E, Muthukumaraswamy SD, Etchells P. Instead of" playing the game" it is time to change the rules: Registered Reports at AIMS Neuroscience and beyond. AIMS Neuroscience 2014;1:4-17.

15. Casals M, Finch CF. Sports Biostatistician: a critical member of all sports science and medicine teams for injury prevention. Inj Prev 2017;23:423-7.

16. Weissgerber TL, Garovic VD, Milin-Lazovic JS, Winham SJ, Obradovic Z, Trzeciakowski JP, et al. Reinventing biostatistics education for basic scientists. PLoS Biol 2016;14:e1002430.

17. Freeman JV, Collier S, Staniforth D, Smith KJ. Innovations in curriculum design: a multi-disciplinary approach to teaching statistics to undergraduate medical students. BMC Med Educ 2008;8:28.

18. Sahai H, Ojeda MM. Problems and challenges of teaching biostatistics to medical students and professionals. Med Teach 1999;21:286-8.

19. Kitchen CM. Nonparametric vs parametric tests of location in biomedical research. Am J Ophthalmol 2009;147:571-2.

20. Zimmerman DW. Invalidation of parametric and nonparametric statistical tests by concurrent violation of two assumptions. J Exp Educ 1998;67:55-68.

21. Hoskin T. Parametric and nonparametric: demystifying the terms. Mayo Clinic. 2012.

22. Sax LJ, Gilmartin SK, Bryant AN. Assessing response rates and nonresponse bias in web and paper surveys. Res High Educ 2003;44:409-32.

23. Yasmeen S, Romano PS, Tancredi DJ, Saito NH, Rainwater J, Kravitz RL. Screening mammography beliefs and recommendations: a web-based survey of primary care physicians. BMC Health Serv Res 2012;12:32.

24. Kim HL, Hollowell CM, Patel RV, Bales GT, Clayman RV, Gerber GS. Use of new technology in endourology and laparoscopy by American urologists: Internet and postal survey. Urology 2000;56:760-5. 